\title{
Hydrometeorology of the Amazon in ERA-40
}

\author{
Alan K. Betts and John H. Ball \\ Atmospheric Research, Pittsford, Vermont \\ PEDRO Viterbo \\ ECMWF, Reading, United Kingdom \\ Aiguo DaI \\ NCAR, * Boulder, Colorado \\ José MARENGO \\ CPTEC-INPE, Cachoeira Paulista, São Paulo, Brazil
}

(Manuscript received 24 November 2004, in final form 2 March 2005)

\begin{abstract}
The hydrometeorology of the Amazon basin in the ERA-40 reanalysis for 1958-2001 is compared with observations of precipitation, temperature, and streamflow. After 1979, the reanalysis over the Amazon has a small cool bias of the order of $-0.35 \mathrm{~K}$, and a small low bias of precipitation of the order of -0.3 $\mathrm{mm}$ day $^{-1}$. In the early years (1958-72), there is a large upward drift in reanalysis precipitation and runoff associated with an upward drift in the atmospheric water vapor in the analysis, and a somewhat smaller downward drift of temperature as precipitation increases. In the presatellite data, there are inhomogeneities in the radiosonde and surface synoptic data, and there were problems with the variational analysis of humidity once satellite radiances were introduced. Approximate bias corrections can be made for precipitation and runoff on an annual basis, but this also removes some of the interannual variability. The reanalysis runoff-precipitation relationship is similar to the observed streamflow-precipitation relation, on an annual water-year basis. Compared to observations, ERA-40 precipitation for the Amazon is low by about $1.3 \mathrm{~mm}$ day $^{-1}$ in the rainy season, and high by a smaller amount in the dry season. The precipitation bias produces a temperature bias in ERA-40 of the opposite sign on the annual time scale. The reanalysis has a small cold temperature bias after 1967, but on an annual time scale it reproduces the interannual variability of the observations. Although the biases in temperature and precipitation in recent decades are small, the difficulties with the analysis of atmospheric water vapor lead to large uncertainty in long-term trends of the water cycle.
\end{abstract}

\section{Introduction}

One of the objectives of the Large-Scale BiosphereAtmosphere Experiment (LBA) is to assess how the Amazon functions as part of the climate system (Silva Dias et al. 2002). Data covering the entire Amazon

\footnotetext{
* The National Center for Atmospheric Research is sponsored by the U.S. National Science Foundation.
}

Corresponding author address: Alan K. Betts, Atmospheric Research, 58 Hendee Lane, Pittsford, VT 05763.

E-mail: akbetts@aol.com basin are sparse, so we depend on models both for data synthesis and to quantify the energy and water cycle. LBA is a component of the Global Energy and Water Cycle Experiment (GEWEX), which has the aim of improving our ability to simulate both water and energy exchange processes in global climate and weather models. One critical question for climate studies is whether the interannual variability and decadal drifts of the water cycle are well-represented in reanalyses. On a global scale, Trenberth and Guillemot (1998) have evaluated the atmospheric moisture and hydrological cycle in the first National Centers for Environmental PredictionNational Center for Atmospheric Research (NCEPNCAR) reanalysis (Kalnay et al. 1996). Costa and Fo- 
ley (1999), using data from the same reanalysis, suggest that the atmospheric transport of water vapor through the Amazon basin has decreased in the $20 \mathrm{yr}, 1976-96$. Roads et al. (2002) analyze the water and energy budgets for the continental-scale experiments using the second NCAR/U.S. Department of Energy (DOE) reanalysis. Zeng (1999) discusses the seasonal cycle and interannual variability from the NASA Goddard Earth Observing System reanalysis (GEOS-1). Marengo (2005) uses the NCEP-NCAR reanalysis, together with precipitation and streamflow data, to describe the hydrometeorology of the Amazon during recent decades. This paper addresses the limited task of describing the hydrometeorology over the Amazon in the recent European Centre for Medium-Range Weather Forecasts (ECMWF) reanalysis. In a separate paper (Betts and Viterbo 2005), we use the model data to analyze the coupling of the land surface, the boundary layer, and the cloud fields over the Amazon, extending the work of Betts (2004).

This paper is one of several using the recent ECMWF reanalysis (Simmons and Gibson 2000) to study different river basins. This was designated ERA-40, although it was extended to cover the $45 \mathrm{yr}$ from September 1957 to August 2002. The analysis system uses a recent version of the model physics, including the land surface scheme described in Van den Hurk et al. (2000), and a $3 \mathrm{D}$ variational assimilation system. The horizontal resolution of the spectral model is triangular truncation at $\mathrm{T}_{\mathrm{L}}-159$, and there are 60 levels in the vertical, including a well-resolved boundary layer and stratosphere. Documentation of the Integrated Forecast System, cycle $23 \mathrm{r} 4$, and a summary and discussion of the observations available at different times during the 40-yr reanalysis can be found online at http:/www.ecmwf.int/ research/era/. Surface energy and water budgets, and near-surface and subsurface variables averaged over river basins, are computed and archived (Kållberg et al. 2004) during the analysis cycle at an hourly time scale. Two earlier papers have assessed the systematic biases in temperature and the surface energy and water budgets of ERA-40 for the Mississippi and Mackenzie River basins (Betts et al. 2003a,b).

\section{Data sources}

For ERA-40, averages over selected basins are output for hourly time intervals (with fluxes accumulated from the full time resolution data) for selected river basins. We averaged the hourly data up to one month, as discussed below. The representation of the Amazon River basin in ERA-40 is shown in Fig. 1. The ERA-40 averages are over all grid points, indicated as dots over

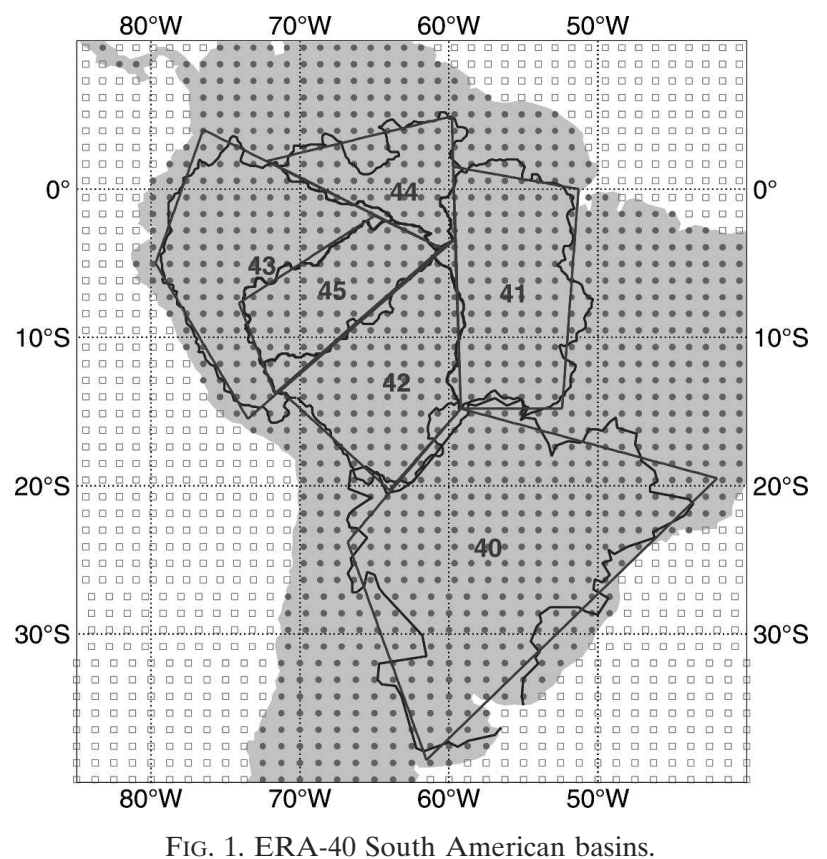

land, inside each polygon, which are approximations to the actual river basin boundaries shown. Basin 41 includes several rivers flowing into the main stem of the Amazon, including the Tapajos and Xingu Rivers; 42 is the Madeira River; 43 is Amazonas; 44 is the Rio Negro; basin 45 is several tributaries to the Amazonas, including the Jurua and the Purus. (Basin 40 for La Plata we do not analyze here.) We then averaged the five basins using the areas in Table 1 to give a monthly mean for the Amazon for comparison with data. Table 1 lists the basin drainage areas in the ECMWF model and their mean elevation, as well as the standard deviation ( $\mathrm{SD}$ ), maximum and minimum heights, all calculated on the model grid. The western basins rise in the Andes, but most of the Amazon basin is at a low elevation.

\section{a. Monthly averages from short-term forecasts}

The model analysis cycle uses 6-h forecasts from analyses at 0000, 0600, 1200, and 1800 UTC. From the

TABLE 1. Amazon subbasin areas in ERA-40.

\begin{tabular}{lrrrrr}
\hline \hline & & \multicolumn{4}{c}{ Model elevation } \\
\cline { 3 - 6 } \multicolumn{1}{c}{ Subbasin } & $\begin{array}{c}\text { ERA-40 } \\
\text { area }\left(\mathrm{km}^{2}\right)\end{array}$ & Mean & SD & Max & Min \\
\hline 41) Tapajos, Xingu & 1375016 & 226 & 121 & 525 & 23 \\
42) Madeira & 1292581 & 456 & 647 & 2998 & 55 \\
43) Amazonas & 1520348 & 770 & 993 & 4064 & 41 \\
44) Negro & 639117 & 205 & 177 & 751 & 34 \\
45) Purus, Jurua & 881229 & 211 & 375 & 2440 & 23 \\
Total area & 5708291 & & & & \\
\hline
\end{tabular}


0000 and 1200 UTC analyses, forecasts were extended to $36 \mathrm{~h}$. Monthly averages were constructed from twicedaily segments of the $0-12,12-24$, and 24-36-h forecasts, verifying at the same time. We shall mostly show monthly means from pairs of $0-12$-h forecasts (FX) from the 0000 and 1200 UTC analyses, and only show the 24-36-h FX in a discussion of the spinup of the model precipitation and evaporation. We also constructed monthly averages from the four 6-hourly segments of the analysis cycle, which we shall use to show the modification of soil moisture in the analysis cycle. For a few years $(1958,1973,1989-94)$, which were at the beginning of the separate ERA-40 analysis streams, basin averages of the 0600 and 1800 UTC 6-h forecasts were not archived, so we do not have a complete water budget for the analysis cycle. Fortunately, combining the two $0-12$-h forecasts from 0000 and 1200 UTC gives almost the same daily precipitation fluxes as combining the four 0-6-h forecasts, so we use these.

\section{b. Distribution of vegetation in ERA-40}

The land-surface scheme in ERA-40 has separate tiles for high (i.e., forests) and low-vegetation classes that are treated differently (Van den Hurk et al. 2000). In ERA-40, each grid square has a fraction and type of both high and low vegetation. Table 2 shows the model vegetation classes in the Amazon basin (with their identifying numbers in square brackets) and their distribution by class and basin. Basins 41, 44, and 45 are more than $90 \%$ forested, while basins 42 and 43 have about $15 \%$ low vegetation.

\section{c. Amazon basin estimates of temperature, precipitation, and river flow}

The observations available to evaluate the model are limited, since data is sparse. Our monthly temperature time series is from Jones and Moberg (2003), and our primary monthly precipitation time series is from Chen

TABLE 2. Distribution of vegetation across the Amazon in ERA- 40 as \% of basin.

\begin{tabular}{lrrrrr}
\hline \multicolumn{1}{c}{ Basin } & 41 & 42 & 43 & 44 & 45 \\
\hline High vegetation & 94 & 85 & 83 & 93 & 97 \\
Deciduous broadleaf [5] & & 3 & & & \\
Evergreen broadleaf [6] & 80 & 5 & 78 & 91 & 97 \\
Interrupted forest [19] & 14 & 77 & 5 & 2 & \\
Low vegetation & 6 & 15 & 17 & 7 & 3 \\
Crops/mixed farming [1] & 1 & 2 & 5 & 0 & 0 \\
Short grass [2] & 0 & 3 & 4 & 0 & 0 \\
Tall grass [7] & 4 & 9 & 7 & 6 & 3 \\
Tundra [9] & & & 0 & & \\
Deciduous shrubs [17] & 0 & & & & \\
\hline
\end{tabular}

et al. (2002): these were area-averaged over the Amazon basin by Dai et al. (2004). We have a separate estimate of annual precipitation from Marengo (2004, 2005), who used 164 stations across the Amazon basin to derive a mean precipitation for the period 1970-98. Both precipitation time series have similar mean values: $5.8 \mathrm{~mm}$ day $^{-1}$ for the corresponding period of 1970-98, but they differ significantly in their total precipitation for some years. For streamflow, we used the data from Marengo (2005) derived from streamflow measurements at Obidos, which have a mean of $2.6 \mathrm{~mm}$ day $^{-1}$ for the period 1970-98.

\section{Comparison of ERA-40 water budget with observations}

The concept behind renanalysis is to use one recent "frozen" data assimilation system to cover the entire period, in contrast to operational analyses in which the modeling system is revised on a frequent basis (as improved numerical or data assimilation schemes and physical parameterizations are introduced, along with increases in resolution). However, although the model is frozen, the data going into the reanalysis has changed markedly over the years from 1958 to 2001, and this has a major impact on the analyses. There are three important epochs in ERA-40: 1958-72, "before satellite data," when the upper-air analysis depends on the sounding data; $1973-86$, starting with the assimilation of the radiances from the first satellite infrared channels on the Vertical Temperature Profiler Radiometer (VTPR) and from late 1978 infrared and microwave sounders from the Television and Infrared Observational Satellite Operational Vertical Sounder (TOVS) suite of instruments; 1987-2001, with the addition of information of radiances from the satellite microwave channels of the Special Sensor Microwave Imager (SSM/I) to the atmospheric water vapor assimilation over the ocean.

As satellites are replaced, they are compared during their overlap period, and bias corrections are introduced for each satellite. However, these corrections do not remove all the inhomogeneities in the record. There are changes in the conventional data: in particular, there are very few Brazilian radisosondes north of $20^{\circ} \mathrm{S}$ before May 1966. In addition, there are fundamental problems in ERA-40 in the variational analysis over the tropical oceans in areas of high-density observations, such as satellite radiances (Troccoli and Kållberg 2004), which impact precipitation over the tropical oceans, as well as over land. Aerosols from volcanic eruptions, such as Pinatubo in 1991/92, affect the infrared emission, and have not been properly accounted 
for. In the next sections, we show how the model precipitation has changed markedly with time, and how it is closely related to the atmospheric moisture analysis.

\section{a. Change of ERA-40 Amazon annual precipitation and runoff with time}

Figure $2 \mathrm{a}$ shows terms in the annual surface water budget for the whole Amazon basin in units of millimeters per day. For precipitation $P$ and evaporation $E$, we show values derived from the $0-12$-h FX and the 24-36-h FX, labeled P12, P36, E12, and E36. We show also an estimate of precipitation, the sum (VIMC + E12) of the 0-12-h FX evaporation and VIMC, which is the vertically integrated moisture convergence for the Amazon basin, derived from the four analysis times at 0000, 0600, 1200, and 1800 UTC. The other terms are runoff, R12, from 0-12-h FX, the annual change of column soil moisture storage (CSM) and the increment of column soil moisture added by the analysis. In the Tropics, unlike at high latitudes (Betts et al. 2003b), the change of precipitation (spinup or spindown) is small in the first $36 \mathrm{~h}$ of the forecast (and evaporation and runoff change even less), although this is not true of atmospheric total column water vapor (TCWV; see Fig. 2b). However model precipitation and runoff both increase sharply from low values in the 1960s to peak in the mid-1970s, and then decline slightly after 1980. These large changes of precipitation and runoff with time are spurious and are caused by errors in the atmospheric moisture analysis. The reanalysis model is run only in short-term forecast mode, so it does not "drift" with time in the sense of a free-running climate model. Instead, every 6-h analysis increments are added as it assimilates a global dataset. However, precipitation in short-term forecasts depends strongly on the precipitable water in the analysis, which has a large variation with time (see next section).

CSM increases from the 1960s to the 1970s, as model precipitation increases and then changes little annually. The ERA-40 analysis modifies soil water in the first three soil layers $(0-7,7-28$, and $28-100 \mathrm{~cm})$, subject to certain constraints, based on analysis increments of 2-m temperature and humidity (Douville et al. 2000). The CSM analysis increment averages about $0.35 \mathrm{~mm}$ day $^{-1}$. It is reduced during the high precipitation period of the mid-1970s, and it is missing in Fig. 1 for some years, because of missing forecasts from the 0600 and 1800 UTC analyses in this river basin archive (see section 2a). This soil water analysis effectively nudges soil water based on the optimal interpolation of errors in the screen level variables, so this helps reduce biases in soil water and evaporation, although some can still be
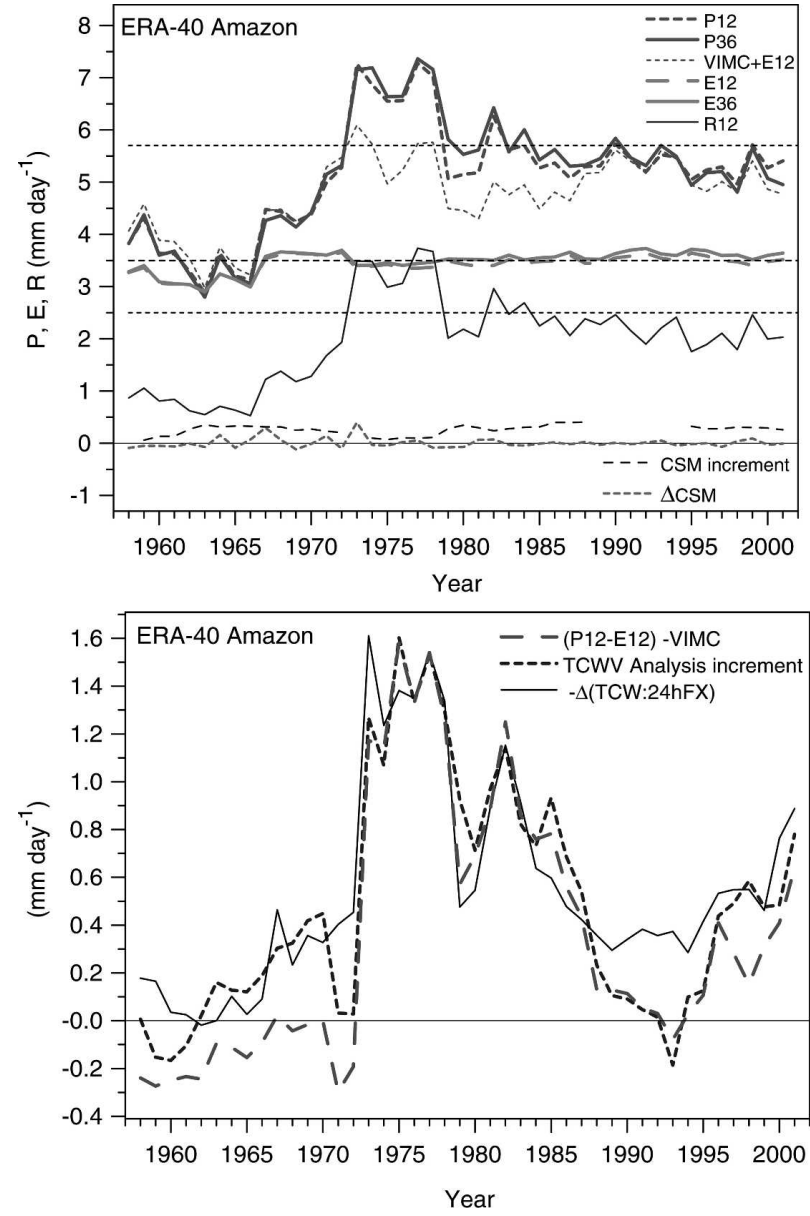

FIG. 2. (a) Terms in the surface water budget in ERA-40 for the Amazon. (b) Comparison of ( $P$-E-VIMC) with TCW analysis increment and 24-h forecast tendency.

seen in Fig. 1. We show dotted reference lines corresponding to $P, E, R=5.7,3.5,2.5 \mathrm{~mm}$ day $^{-1}$, which are close to long-term means for the Amazon (see Fig. 4, later).

The precipitation estimate from VIMC is close to the model precipitation except for the period, 1973-87, when it is much lower. The reason for this lies in the large model analysis increments for atmospheric water vapor during this period. Figure $2 \mathrm{~b}$ shows that the difference between P12 and E12, a forecast quantity, and VIMC, an analysis quantity, is very close, after 1972 , to the mean of the analysis increments. In the mid-1970s, the analysis is adding about $1.4 \mathrm{~mm} \mathrm{day}^{-1}$ to the atmospheric TCWV. The third curve (solid) is the change of the model atmospheric water storage term (TCW, including a tiny contribution from cloud water and ice) in a 24-h forecast (with the sign reversed). This too closely follows the analysis increment in the period 1972-86. We conclude that during this period the analysis adds 
TCWV, which is rained out in the first $24 \mathrm{~h}$, which increases the model precipitation.

\section{b. Comparison of ERA-40 precipitation and runoff with observations for water years}

The next two figures compare ERA-40 annual precipitation and runoff with data for the Amazon. Our year is now the "water year," running from September to August, with the water year ending in August 1959 labeled as 1959. Figure 3 (upper) shows (left-hand scale) both annual precipitation and the bias of ERA40 from the Dai et al. (2004) observational record (offset by the $44-\mathrm{yr}$ mean of $5.7 \mathrm{~mm}$ ), and (right-hand scale) atmospheric total column water vapor. It is clear that changes in the model precipitation over the Amazon and the bias from observations are both closely correlated with changes in TCWV in the analysis, which shows a large increase from the 1960s to the mid-1970s. The pattern of the TCWV analysis increments in Fig. 2b is also similar to the pattern of TCWV in Fig. 3a for the period 1973-86.

Figure $3 \mathrm{~b}$ shows the regression lines for annual $\mathrm{P}$ and $\mathrm{R}$ and the bias of $\mathrm{P}$ from the observations against TCWV. These large changes in TCWV during the period of ERA-40 are due to humidity analysis errors, not to real circulation changes (Troccoli and Kållberg 2004). The large 1972/73 discontinuity occurs with the introduction of the humidity radiance channel on the first VTPR satellite. There was a fundamental problem in the variational analysis of humidity over the tropical oceans in areas of high-density satellite radiance observations. Troccoli and Kållberg (2004) propose a method to correct oceanic precipitation, which shows significant but smaller changes with time, linked to the overall usage of remote sensing information. The time trends shown here over the Amazon can also be seen at high latitudes over the Mackenzie River basin (Betts et al. 2003b). The smaller discontinuity in ERA-40 between 1966 and 1967 in Amazonian P and TCWV (and $\mathrm{E}$ in Fig. 2a) may be linked to a major change in the conventional data. Before May 1966, there are very few Brazilian radiosondes in ERA-40 north of $20^{\circ} \mathrm{S}$ (although there is pilot balloon data), and the Brazilian surface synoptic data are not included before January 1967.

However, since the bias of the model precipitation from observations appears linearly related to TCWV (lower curve in Fig. 3b), a linear correction, based on the slope of the regression lines in Fig. 3b, will remove much of the model bias in annual $\mathrm{P}$ and $\mathrm{E}$. Noting that at $\mathrm{TCWV}=44.8 \mathrm{~kg} \mathrm{~m}^{-2}$, the model precipitation bias is zero (from the Dai et al. 2004 mean, representative of
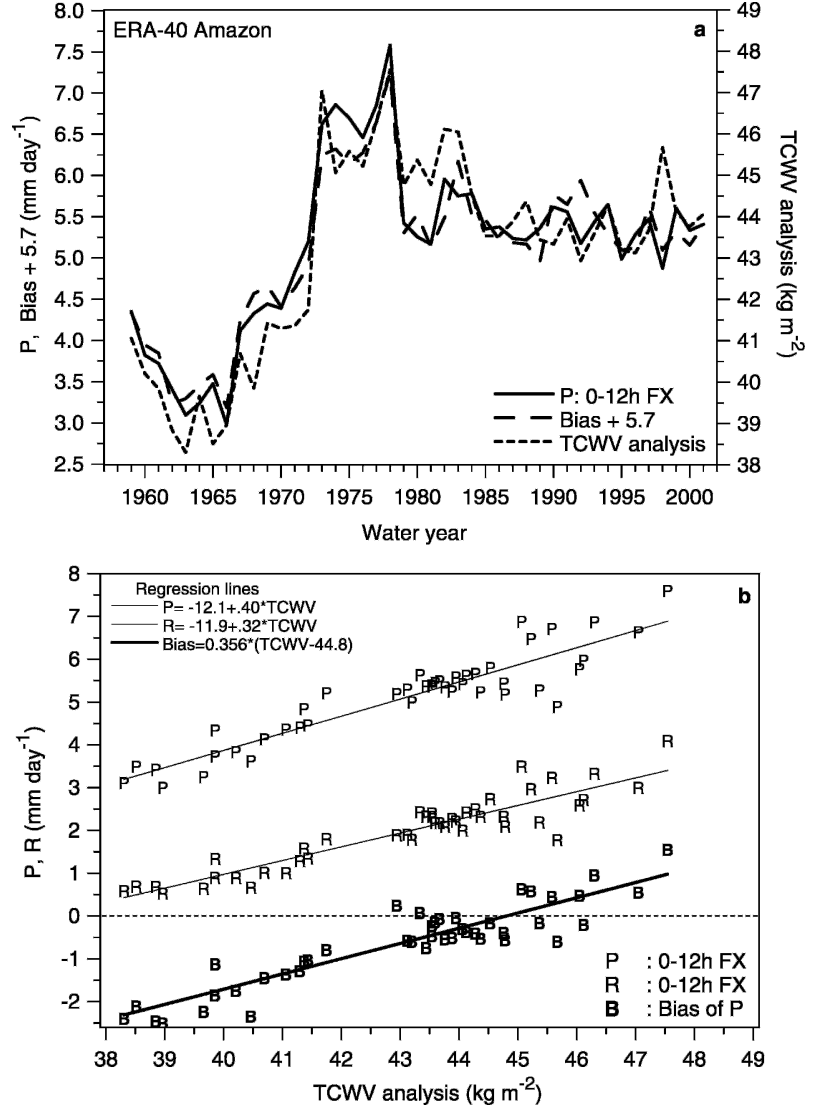

FIG. 3. (a) Annual precipitation, precipitation bias, and total column water vapor in ERA-40; (b) regression of annual precipitation, precipitation bias, and runoff against mean total column water vapor.

the period after 1980), we applied these corrections to the reanalysis annual precipitation and runoff

$$
\begin{aligned}
& P_{c}=P-0.40 \times(\mathrm{TCWV}-44.8) \\
& R_{c}=R-0.32 \times(\mathrm{TCWV}-44.8) .
\end{aligned}
$$

For the recent period, 1980-2001, mean analysis TCWV $=44.1 \mathrm{~kg} \mathrm{~m}^{-2}$, so (1) increases precipitation by about $0.3 \mathrm{~mm} \mathrm{day}^{-1}$, bringing the model precipitation into agreement with the Dai et al. mean for this period.

Figure 4a shows $P, R, P_{c}, R_{c}$ corrected using (1), (2) together with observed annual precipitation, $P_{\mathrm{obs}}$, from Dai et al. (2004) and precipitation and Amazon streamflow, $S_{\text {obs }}$, from Marengo (2005). The correction removes the large spurious model changes between the decades, but the residual annual variability of $P_{c}, R_{c}$ is not that well correlated with the observed Amazon annual precipitation and streamflow. We also show for comparison the Southern Oscillation index (SOI), defined as the difference in sea level pressure between Tahiti and Darwin (Trenberth 1984). Many previous 

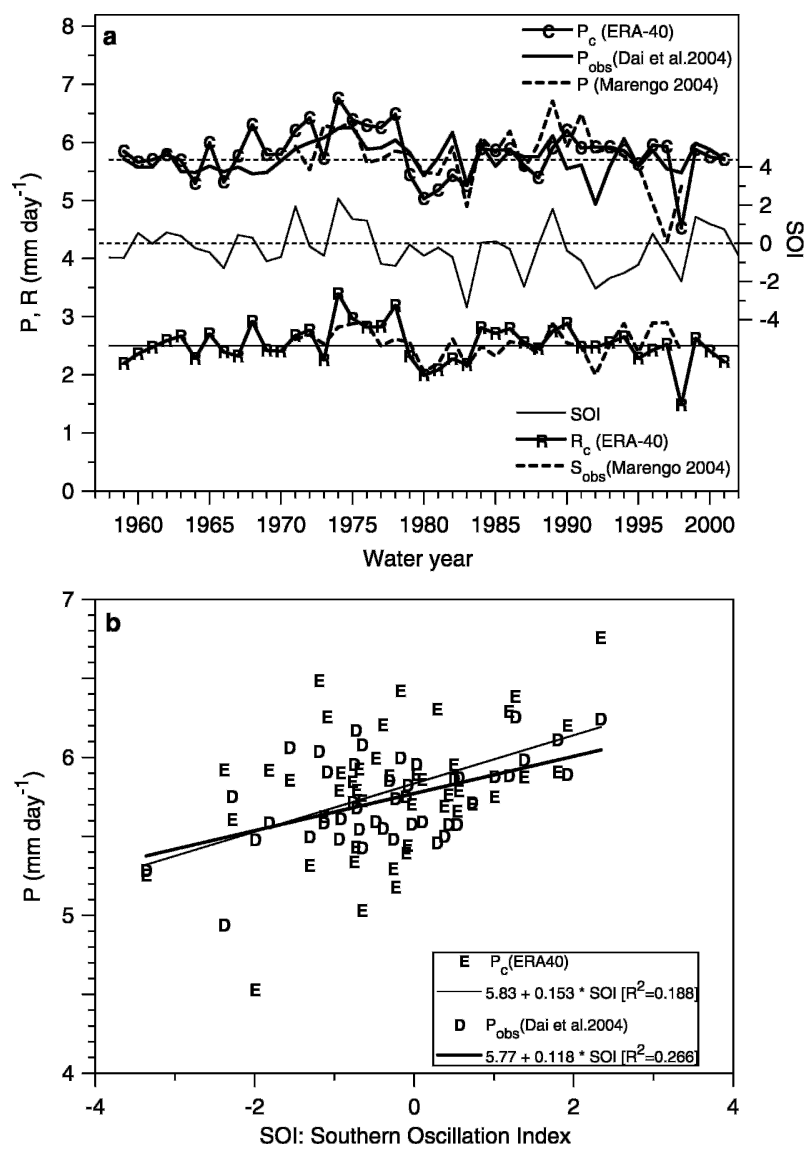

FIG. 4. (a) Comparison of corrected annual mean precipitation and runoff in ERA-40 with observations for the Amazon for water years, together with Southern Oscillation index (SOI). (b) ERA-40 $P_{c}$ and Dai et al. (2004) $P_{\text {obs }}$ against SOI (with regression lines).

studies have shown the link between the SOI (and tropical Pacific sea surface temperatures) and Amazonian rainfall (e.g., Marengo 1992; Liebmann and Marengo 2001). Figure $4 \mathrm{~b}$ shows the correlation between annual precipitation, $P_{c}$ and $P_{\text {obs }}$ and the SOI (for the same water years). The SOI is better correlated with the observations than the model, but it appears that some of the interannual variability remains in ERA-40.

Figure 5 shows three relationships. The upper cloud of points, in the right-hand scale, is the corrected ERA$40 P_{c}$ against the Dai et al. $P_{\text {obs }}$. Although our correction removes the bias (we show the 1-to-1 line for visual reference), the correlation is clearly poor (not shown, $R^{2}=0.18$ ). Below on the left-hand scale is ERA-40 $R_{c}$ against $P_{c}$, and Amazon $S_{\text {obs }}$ against $P_{\text {obs }}$, together with the regression lines. The precipitation-runoff relations of reanalysis model and the observations are similar on an annual basis, although note that the ERA-40 hydrol- ogy model is a very simple one with primarily deep drainage with nonfrozen soils (Van den Hurk et al. 2000), no river routing, and no representation of the seasonally flooded regions of the Amazon. The model deep drainage lags precipitation by only a few weeks, while the streamflow at Obidos lags basin precipitation by several months; but when we compare annual streamflow for water years (September-August), the impact of these different lags is minimized. Note that on Fig. 4a the two estimates of Amazonian rainfall are themselves not well correlated after 1990. The Dai et al. (2004) precipitation time series seems more representative, as it is correlated with the annual Amazon streamflow (Fig. 5). In contrast, the Marengo (2005) annual precipitation time series is poorly correlated with the annual streamflow (see Fig. 4a). In the reanalysis, the correlation between $\mathrm{P}$ and TCWV exists on monthly as well as annual time scales (see next section), so it is probable that the corrections (1) and (2) remove some real interannual variability as well as spurious interannual analysis variability. Our conclusion is that the mean precipitation and runoff over the Amazon from ERA-40 after 1980 are close to (but slightly below) the observed mean for the same period, and with a bias correction, there is broad agreement for the 44-yr period. However uncertainties in the atmospheric water vapor analysis in ERA-40 lead to uncertainty in the long-term trends of precipitation and some uncertainty in the model interannual variability.

\section{c. Correlation of precipitation and TCWV on monthly time scales}

Using Fig. $3 \mathrm{a}$ as a guide we divided ERA-40 into three time periods:

1958-72, an early "dry period," corresponding to the presatellite data; 1973-78, a "wet" period, corresponding to the early infrared satellite data; and 1979-2001, the recent period when satellite microwave sounding data was also assimilated. (There are some differences between 1979-87 and 19882001, but we have chosen not to split this period.)

Figure 6 plots (upper) monthly ERA-40 0-12-h FX precipitation against monthly TCWV, with the numbers indicating the three time periods, and (lower) the corresponding monthly precipitation bias from the Dai et al. observations. A relationship between model precipitation and TCWV also exists on monthly time scales, rather similar to the regression fit shown in Fig. $3 \mathrm{~b}$ (reproduced here as the solid line). However, some nonlinearity can be seen, and there is a distribution shift between the three time periods. The lower scat- 


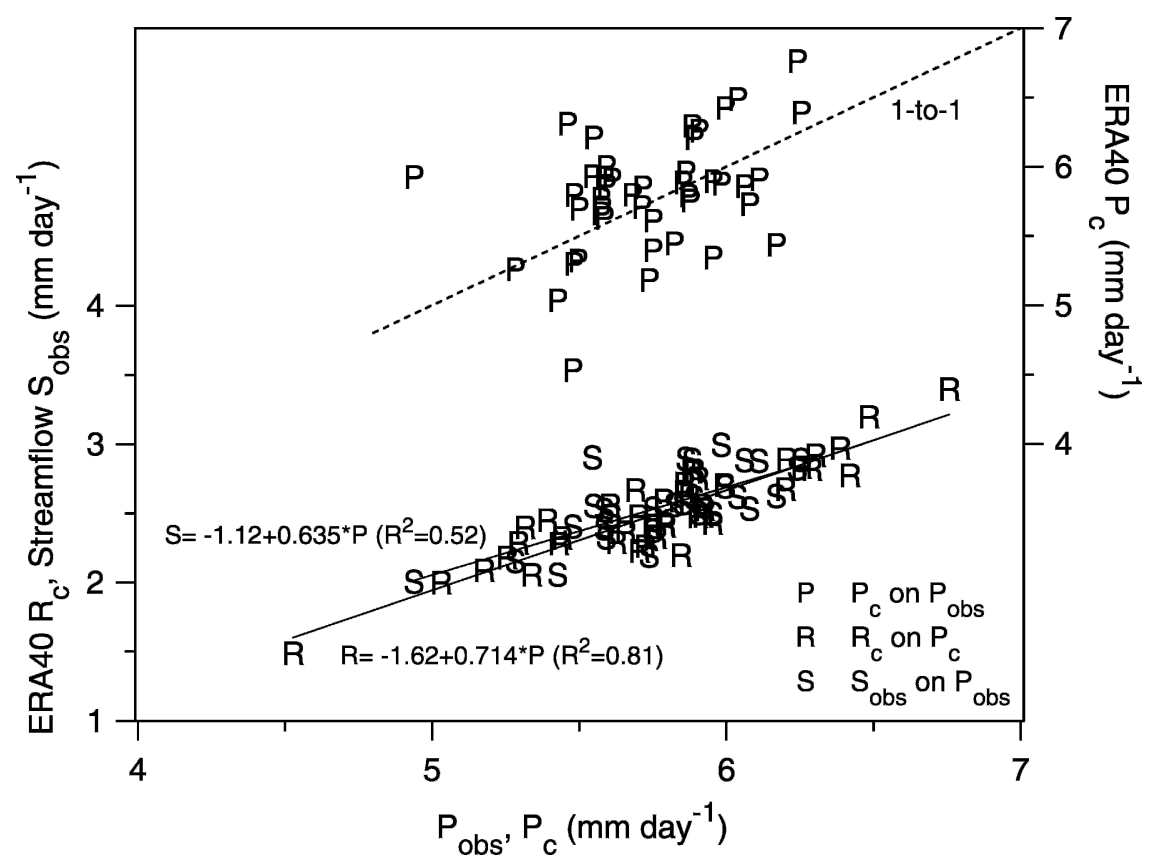

FIG. 5. ERA-40 $P_{c}$ against $P_{\text {obs }}$ (with 1-to-1 line), ERA-40 $R_{c}$ against $P_{c}$, and Amazon $S_{\text {obs }}$ against $P_{\mathrm{obs}}$ (with regression lines).

terplots show that the model precipitation has in addition a distinct seasonal bias. For example, for the recent period labeled 3, the precipitation bias is positive in the dry season and negative in the wet season. The width of the bias distribution is relatively small for this period, 1979-2001. This suggests that ERA-40 does reproduce

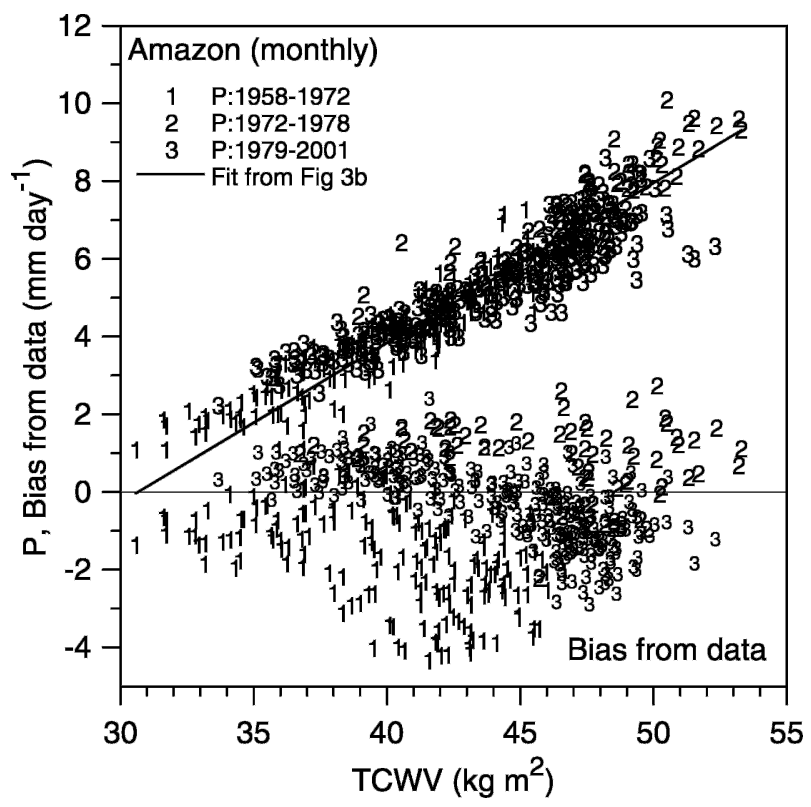

FIG. 6. Monthly precipitation and precipitation bias against TCWV for three time periods of ERA-40. some of the seasonal variability of the data, and a more refined precipitation correction method could perhaps be developed, which accounts for the seasonal variation.

\section{d. Mean annual cycle of precipitation and TCWV for Amazon}

Figure 7 shows the mean annual cycle averaged for the three periods. The Dai et al. observations in Fig. 7a show an annual cycle which is rather similar for the three periods, with only slightly more precipitation in the mid-1970s, in sharp contrast to the ERA-40 0-12-h FX precipitation in Fig. 7b. The model bias in Fig. 7d, however, shows a characteristic annual cycle with low precipitation in the rainy season and high precipitation in the dry season. The pattern shifts vertically for the different periods, and there is also a sign of extra precipitation for the "wet" middle time period in May-June and September-October (however, since this period is the shortest, only $6 \mathrm{yr}$, this might be sampling effect). For the recent period, when ERA-40 has a small negative annual bias of precipitation $(\sim-0.3$ $\mathrm{mm}$ day $^{-1}$ ), it has a positive dry season bias, peaking at $0.8 \mathrm{~mm} \mathrm{day}{ }^{-1}$ in August and a larger wet season negative bias, peaking at $-1.4 \mathrm{~mm} \mathrm{day}^{-1}$ in March, compared with the Dai et al. (2004) dataset. The precipitation estimate in Fig. 7c from VIMC $+E$ has less of a bias in the dry season, but remains lower than 

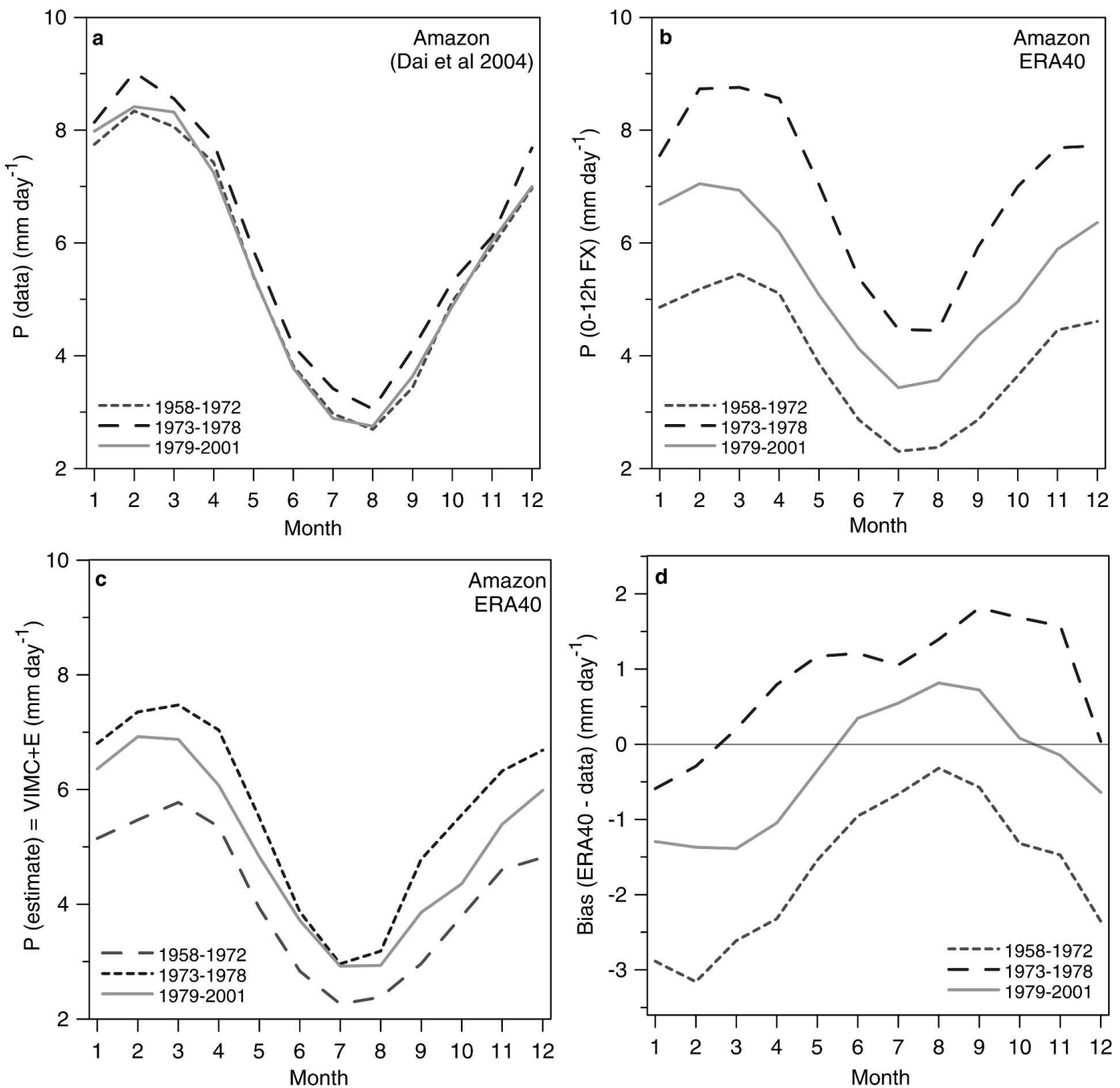

FIG. 7. Mean annual cycle of (a) observed precipitation, (b) ERA-40 0-12 h FX precipitation, (c) precipitation estimate from moisture convergence, and (d) ERA-40 precipitation bias.

observed in the rainy season. VIMC $+E$ has less of a spread for the three periods than the model $P$, primarily because (VIMC $+E)<P$ from 1973 to 1986 (Fig. 2a), when the model TCWV analysis increments are large (Fig. 2b).

\section{Temperature comparison}

\section{a. Annual mean temperature: Correlation with precipitation}

Figure 8a shows the time series of annual mean 2-m temperature for the Amazon from ERA-40 (derived from hourly $0-12$-h forecasts by interpolating between the lowest model level and the surface) and the Dai et al. data. There is a marked shift in ERA-40 from a warm to a cool bias in 1967 at the same time that the
Brazilian surface synoptic data is included in ERA-40. Figure $8 \mathrm{~b}$ shows that on an annual basis, ERA-40 temperature is warm when the model annual precipitation is low and cool when model precipitation is high. Figure 8d shows the regression of ERA-40 $T$ on $P$, and Fig. 8c shows the corresponding regression for the data, which has a far smaller range than the model (which suffers from the drifts in TCWV and $P$ shown in Fig. 3a). Figure $8 \mathrm{a}$ also suggests that the reanalysis largely reproduces the annual variability of the data after 1966 (note that ERA-40 has an additional cool bias in the mid1970s when model precipitation is highest). Figure 9 plots ERA-40 annual $T$ against the data for the period 1967-2001. The wet years of 1974-78 are the cool outliers marked. Two lines are shown: the simple linear regression line (fitted to all the points), which is essentially the same as the line $T$ :data -0.45 . 

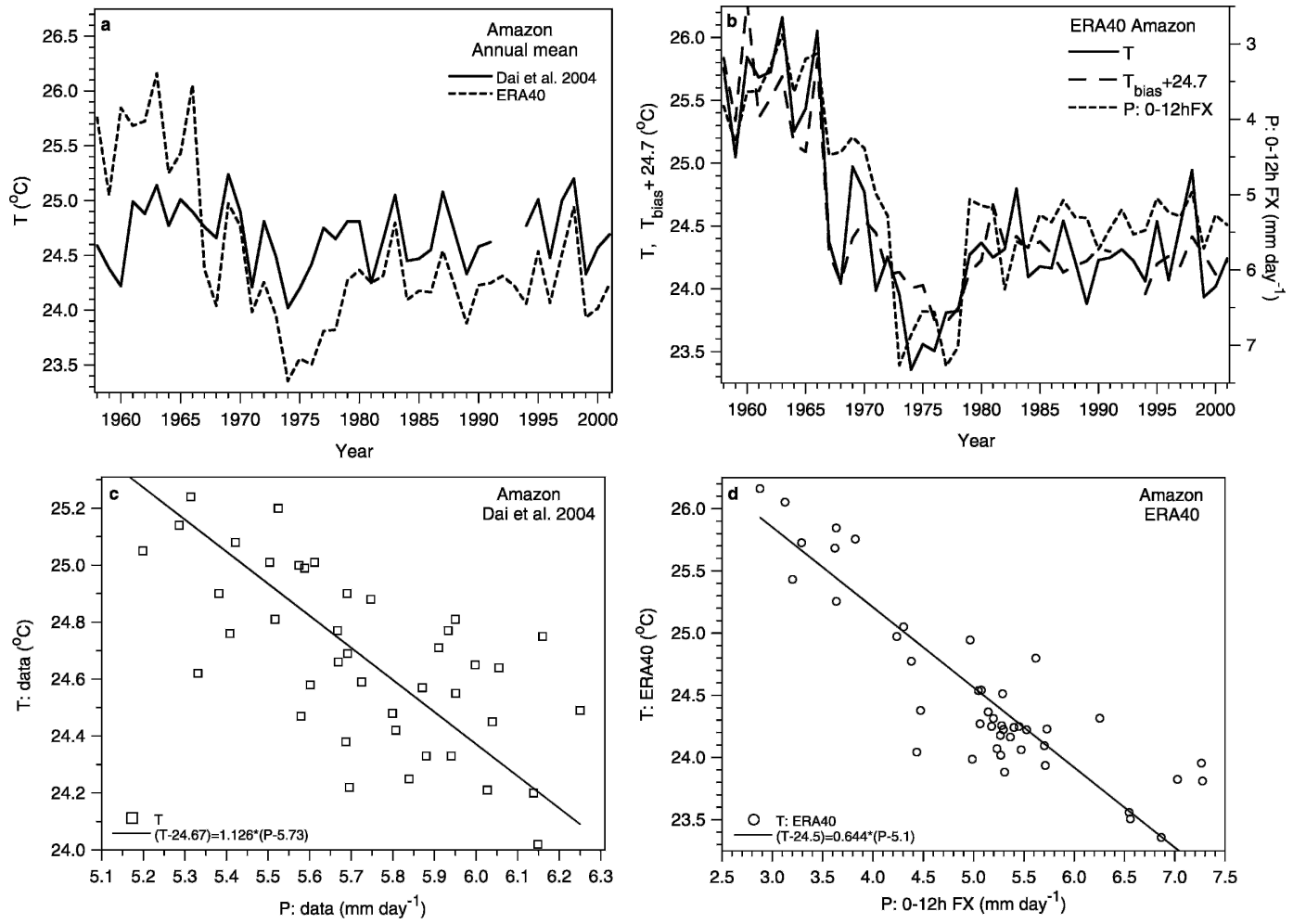

FIG. 8. (a) Comparison of annual mean observed and ERA-40 2-m temperature; (b) time series of ERA-40 2-m temperature, temperature bias, and precipitation; (c) scatterplot of observed 2-m temperature against precipitation; and (d) as (c) for ERA-40.

\section{b. Annual cycle of temperature}

Figure 10 compares the observed annual cycle of temperature with the reanalysis, averaged into three periods, changed slightly from those defined in section 3c. We shortened the early "dry warm" period to 1958-66, kept the wet period of 1973-78 (although

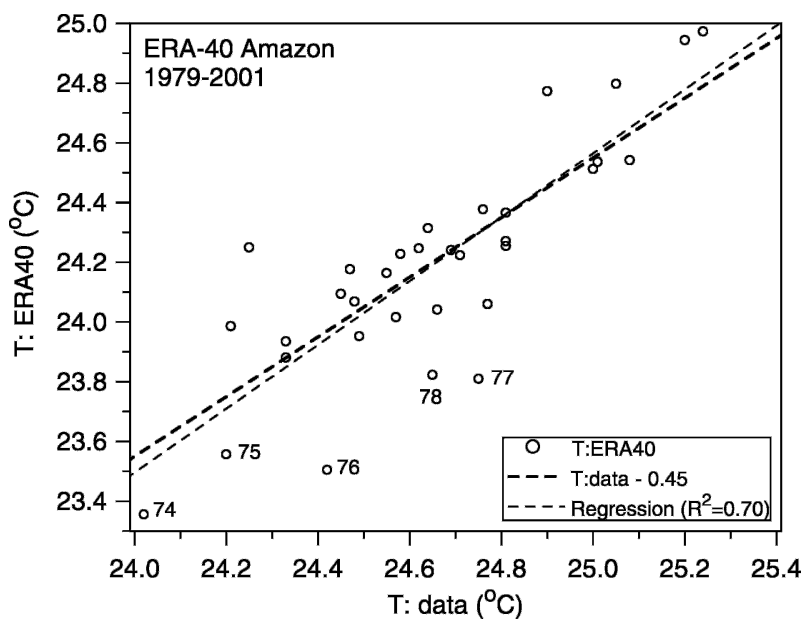

FIG. 9. ERA-40 annual mean temperature plotted against data.
1973 does not have as cool a temperature bias), and composited together groups of years: 1967-72, 1979-91, 1994-2001. The two years 1992-93 are incomplete in the observations, so these were omitted. Figure 10a shows that the observed annual cycle of temperature is very similar for the three time composites, unlike Fig. 10b for ERA-40. Figure 10c shows the model bias. In the early years, the bias is generally warm, peaking in August at $1.8^{\circ} \mathrm{C}$, but it is near zero at the end of the rainy season. The middle curve, which includes most of the recent years after 1979, shows that ERA-40 has a cold bias, larger in the rainy season, and rather small in the dry season. The cold bias gets larger in the wet years of the mid 1970s, as seen in the annual mean in Fig. 9.

\section{Conclusions}

We compare the hydrometeorology of the Amazon basin in ERA-40 for 1958-2001 with observations of precipitation, temperature, and streamflow. After 1979, the reanalysis over the Amazon has a small cool bias of order $-0.35 \mathrm{~K}$, and a small low bias of precipitation of order $-0.3 \mathrm{~mm} \mathrm{day}{ }^{-1}$. Although the biases in tempera- 

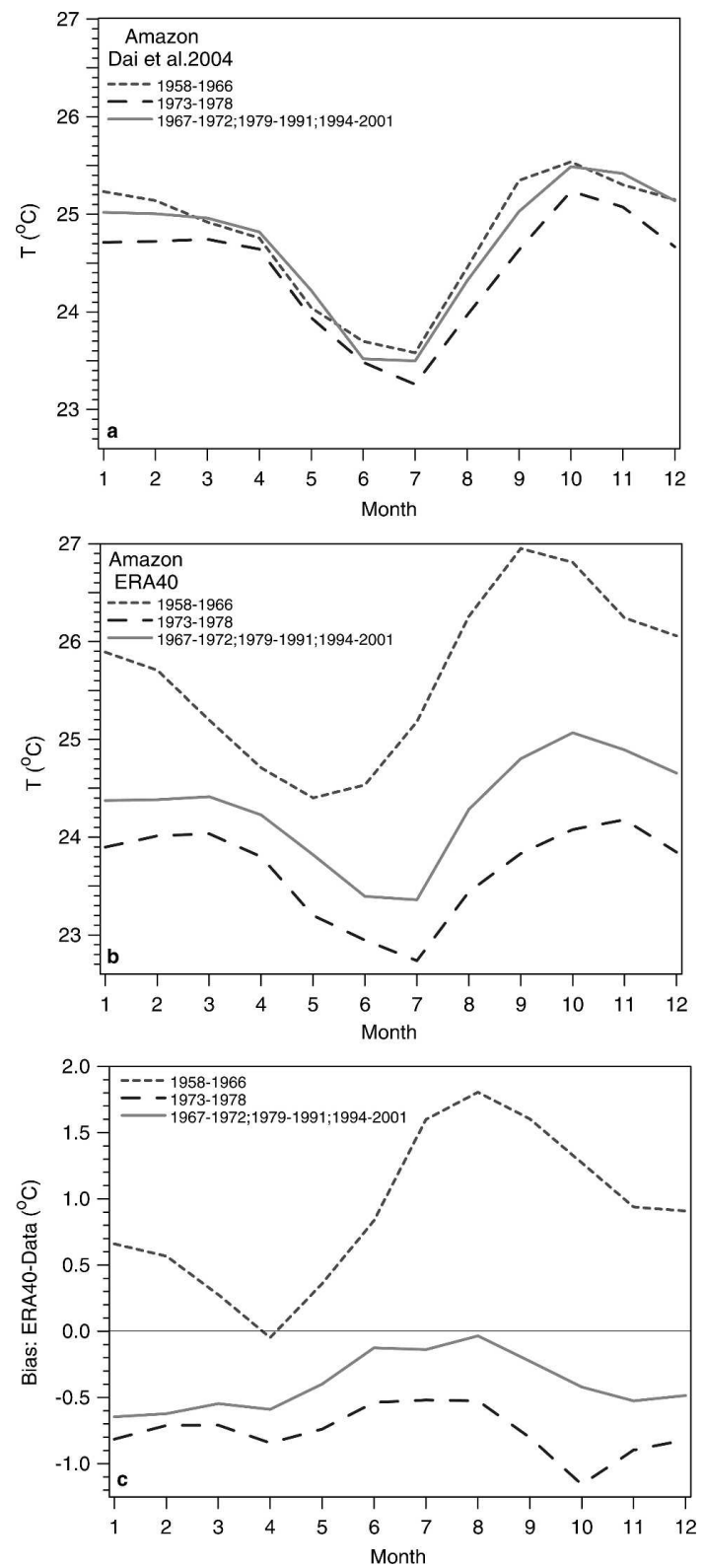

FIG. 10. Mean annual cycle of (a) observed 2-m temperature, (b) ERA-40 2-m temperature, and (c) ERA-40 2-m temperature bias.

ture and precipitation in recent decades are small, difficulties with the analysis of atmospheric water vapor over the period of the reanalysis lead to great uncertainty in the long-term trends of the water cycle. In the early years (1958-72), there is a large upward drift in the reanalysis precipitation and runoff associated with an upward drift in the atmospheric water vapor analysis in the presatellite data period, and a corresponding downward drift of mean temperature as precipitation increases. In the period of the first infrared sounding satellite data (1973-78), precipitation has a high bias and temperature has a correspondingly larger cool bias. Approximate bias corrections can be made for precipitation and runoff on an annual basis, which gives the correct long-term mean, but this also removes some of the interannual variability, and leaves a corrected precipitation time series that is poorly correlated with observations. Thus this reanalysis cannot answer many questions relating to long-term trends in the global hydrological cycle over the past $40 \mathrm{yr}$. On an annual water year basis, the reanalysis runoff-precipitation relationship is similar to the observed streamflow-precipitation relation. Seasonally, ERA-40 precipitation for the Amazon (after 1979) is low by about $1.3 \mathrm{~mm} \mathrm{day}^{-1}$ in the rainy season compared to observations, and high by a smaller amount in the dry season. Changes in the annual precipitation in ERA-40 produce an annual temperature bias of the opposite sign.

One significant change in the conventional data impacts the reanalysis. Before May 1966, there are very few Brazilian radiosondes in ERA-40 north of $20^{\circ} \mathrm{S}$, although there is pilot balloon data. The Brazilian surface synoptic data are not included before January 1967, and with its introduction, there is a marked shift in ERA-40 from a warm to a cool bias in 2-m temperature. From 1967, the reanalysis model has a small cold temperature bias, but on an annual time scale it reproduces much of the interannual variability of the observations. Seasonally, the cold bias of the reanalysis is a little larger in the rainy season of the austral summer (despite the low-precipitation bias) than in the dry season.

Reanalyses have proved useful for the study of the changes in the atmospheric circulation, but the hope that reanalyses could also be used to study climatic trends in tropical precipitation has not yet been realized. A further reanalysis of recent decades of the satellite era, incorporating a new humidity analysis, is under development, and it is expected that it will improve the description of the tropical hydrological cycle.

Acknowledgments. Alan Betts acknowledges support from NASA under Grant NAS5-11578 and from NSF under Grant ATM-9988618, and from ECMWF for travel. Aiguo Dai is partly supported by the NCAR Water Cycle Across Scales Initiative. It is a pleasure to acknowledge the entire ERA-40 team for their assistance in (i) testing the surface model in preliminary yearly runs of the system, (ii) setting up the basin model diagnostics on which this manuscript is based, and (iii) providing insight into the data assimilation performance and data usage. We wish to thank an anonymous reviewer for several valuable suggestions. 


\section{REFERENCES}

Betts, A. K., 2004: Understanding hydrometeorology using global models: American Meteorological Society Robert E. Horton Lecture, January 14, 2004, Seattle. Bull. Amer. Meteor. Soc, 85, 1673-1688.

— cloud-field coupling over the southwestern Amazon in ERA40. J. Geophys. Res., 110, D14108, doi:10.1029/2004JD005702.

_ J. J. Ball, M. Bosilovich, P. Viterbo, Y.-C. Zhang, and W. B. Rossow, 2003a: Intercomparison of Water and Energy Budgets for five Mississippi Sub-basins between ECMWF Reanalysis (ERA-40) and NASA-DAO fvGCM for 1990-1999. J. Geophys. Res., 108, 8618, doi:10.1029/2002JD003127.

_ J. H. Ball, and P. Viterbo, 2003b: Evaluation of the ERA-40 surface water budget and surface temperature for the Mackenzie River basin. J. Hydrometeor., 4, 1194-1211.

Chen, M., P. Xie, L. E. Janowiak, and A. Arkin, 2002: Global land precipitation: A 50-yr monthly analysis based on gauge observations. J. Hydrometeor., 3, 249-266.

Costa, M. H., and J. A. Foley, 1999: Trends in the hydrologic cycle over the Amazon basin. J. Geophys. Res., 104, 14 189-14 198.

Dai, A., K. E. Trenberth, and T. Qian, 2004: A global dataset of Palmer severity index for 1870-2002: Relationship with soil moisture and effects of surface warming. J. Hydrometeor., 5, 1117-1130.

Douville, H., P. Viterbo, J.-F. Mahfouf, and A. C. M. Beljaars, 2000: Evaluation of optimal interpolation and nudging techniques for soil moisture analysis using FIFE data. Mon. Wea. Rev., 128, 1733-1756.

Jones, P. D., and A. Moberg, 2003: Hemispheric and large-scale surface air temperature variations: An extensive revision and an update to 2001. J. Climate, 16, 206-223.

Kållberg, P., A. Simmons, S. Uppala, and M. Fuentes, 2004: The ERA-40 archive. ERA-40 Project Rep. 17, ECMWF, 31 pp.
Kalnay, E., and Coauthors, 1996: The NCEP/NCAR 40-Year Reanalysis Project. Bull. Amer. Meteor. Soc., 77, 437-471.

Liebmann, B., and J. A. Marengo, 2001: Interannual variability of the rainy season and rainfall in the Brazilian Amazon Basin. J. Climate, 14, 4308-4318.

Marengo, J. A., 1992: Interannual variability of surface climate in the Amazon Basin. Int. J. Climatol., 12 (8), 853-863.

_ 2004: Interdecadal variability and trends of rainfall across the Amazon basin. Theor. Appl. Climatol., 78, 79-96.

— 2005: Characteristics and spatio-temporal variability of the Amazon River basin water budget. Climate Dyn., 24, 11-22.

Roads, J., M. Kanimitsu, and R. Stewart, 2002: CSE water and energy budgets in the NCEP/DOE reanalysis-II. J. Hydrometeor., 3, 227-248.

Silva Dias, M. A. F., and Coauthors, 2002: Cloud and rain processes in a biosphere-atmosphere interaction context in the Amazon region. J. Geophys. Res., 107, 8072, doi:10.1029/ 2001JD000335.

Simmons, A. J., and J. K. Gibson, 2000: The ERA-40 Project Plan. ERA-40 Project Rep. Series No. 1, ECMWF, 63 pp.

Trenberth, K. E., 1984: Signal versus noise in the Southern Oscillation. Mon. Wea. Rev., 112, 326-332.

_ , and C. J. Guillemot, 1998: Evaluation of the atmospheric moisture and hydrological cycle in the NCEP/NCAR reanalyses. Climate Dyn., 14, 213-231.

Troccoli, A., and P. Kållberg, 2004: Precipitation correction in the ERA-40 reanalyses. ERA-40 Project Report Series No. 13, ECMWF, 6 pp.

Van den Hurk, B. J. J. M., P. Viterbo, A. C. M. Beljaars, and A. K. Betts, 2000: Offline validation of the ERA40 surface scheme. ECMWF Tech. Memo 295, ECMWF, 43 pp.

Zeng, N., 1999: Seasonal cycle and interannual variability in the Amazon hydrologic cycle. J. Geophys. Res., 104, 9097-9106. 